
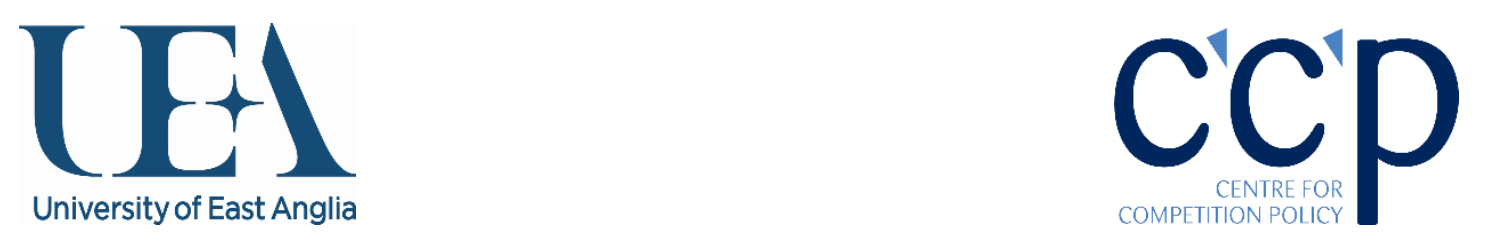

\title{
The deterrent effect of anti-cartel enforcement: A tale of two tails
}

\author{
Iwan Bos \\ Department of Organisation and Strategy \\ Maastricht University \\ Stephen Davies \\ Centre for Competition Policy \& School of Economics \\ University of East Anglia \\ Peter L. Ormosi \\ Centre for Competition Policy \& Norwich Business School \\ University of East Anglia \\ CCP Working Paper 14-6 v2
}

\begin{abstract}
Very little is known empirically about deterred cartels. Therefore, although the characteristics of detected cartels are well documented, it is unclear that they are a representative sample. If deterred or undetected cartels differ systematically from the detected, many of our conventional empirical wisdoms could be subject to sample selection bias. Similarly, the impact of cartel policy, based only on prosecuted cases, could be systematically under-estimated. This paper addresses this gap in our knowledge, and explores how far a key characteristic - the overcharge - differs between deterred and undeterred cartels. First we examine an existing well-known database on cartels and find that the distribution of overcharge for legal cartels has significantly greater mass in its tails than the distribution for illegal cartels. Taking legal cartels as a proxy for a world without enforcement policy, this suggests that it is the lowest and highest overcharge cartels which are most likely to be deterred, or undetected, by cartel enforcement policy. Second, we summon a theoretical model of cartel formation to show that, under very reasonable assumptions, it is deterrence that explains the reduced occurrence of low and high overcharge cartels when faced with antitrust enforcement.
\end{abstract}

Contact Details:

Peter L. Ormosi p.ormosi@uea.ac.uk

The authors wish to acknowledge the contribution of the ESRC who supported their research through Centre for Competition Policy funding (ref: RES-578-28-0002). 


\title{
The deterrent effect of anti-cartel enforcement: A tale of two tails*
}

\author{
Iwan Bos ${ }^{\dagger}$ Stephen Davies; Peter L. Ormosi ${ }^{\S}$
}

November 5, 2015

\begin{abstract}
Very little is known empirically about deterred cartels. Therefore, although the characteristics of detected cartels are well documented, it is unclear that they are a representative sample. If deterred or undetected cartels differ systematically from the detected, many of our conventional empirical wisdoms could be subject to sample selection bias. Similarly, the impact of cartel policy, based only on prosecuted cases, could be systematically under-estimated. This paper addresses this gap in our knowledge, and explores how far a key characteristic - the overcharge - differs between deterred and undeterred cartels. First we examine an existing well-known database on cartels and find that the distribution of overcharge for legal cartels has significantly greater mass in its tails than the distribution for illegal cartels. Taking legal cartels as a proxy for a world without enforcement policy, this suggests that it is the lowest and highest overcharge cartels which are most likely to be deterred, or undetected, by cartel enforcement policy. Second, we summon a theoretical model of cartel formation to show that, under very reasonable assumptions, it is deterrence that explains the reduced occurrence of low and high overcharge cartels when faced with antitrust enforcement.
\end{abstract}

${ }^{*}$ We are grateful for useful comments to Luca Aguzzoni, Morten Hviid, Johannes Paha, Ronald Peeters and participants of the 4th International Workshop: Economics of Competition and Industrial Organization in Cape Town, the CMA-DG COMP Workshop on Looking Beyond the Direct Effects of the Work of Competition Authorities, the DIW Berlin and CCP Norwich Seminar Series, and to David Reader for the research assistance. We are also in debt to Professor John Connor for making his cartel overcharge dataset available. The support of the Centre for Competition Policy is gratefully acknowledged. The usual disclaimer applies.

${ }^{\dagger}$ Maastricht University, Department of Organisation and Strategy, e-mail: i.bos@maastrichtuniversity.nl

${ }^{\ddagger}$ School of Economics and Centre for Competition Policy, University of East Anglia, NR4 7TJ, Norwich, United Kingdom, e-mail: s.w.davies@uea.ac.uk

$\S$ Norwich Business School and Centre for Competition Policy, University of East Anglia, NR4 7TJ, Norwich, United Kingdom, email: p.ormosi@uea.ac.uk 
Keywords: cartel deterrence, cartel overcharge, consumer harm

JEL Classification codes: C46, K14, K21, L41

\section{Introduction}

Anti-cartel policy is an integral and mature part of the competition regimes of nearly all countries in the world. With policy in place and cases documented for many years in most jurisdictions, we now have a rich source of information on 'what cartels do'. This is especially true for the European Union, for which the Commission (EC) has published its very detailed decision documents for over 25 years. These and similar reports from other agencies have supported a large volume of academic literature, and facts have emerged which have gained the status of conventional wisdoms. For instance, on average, cartels last for roughly 5-7 years, have 4-7 members, and set a substantial overcharge over the competitive price - perhaps in the region of $20 \%{ }^{1}$ For policy makers, these documented cases have been employed in a variety of ways, notably to make assessments of the value of cartel policy. ${ }^{2}$

However, an important limitation on this literature and conventional wisdoms is that they are all based on cartels which are observed and successfully prosecuted, and necessarily ignore those other cartels which are not observed - either because they go undetected or because they are deterred.

The unobserved cases are also of interest for a variety of reasons. Deterrence is one of the most important objectives of any law, and when quantifying the impact of cartel law, an allowance should be included ideally for the amount of deterrence not only how many cases, but also how harmful they would be if there was no anticartel enforcement. On the other hand, if the large majority of cartels go undetected, this must be seen as an important shortcoming when assessing the record of the competition authorities (CAs). Moreover, if the characteristics of undetected and deterred cartels differ significantly from those that are observed, we will have a biased understanding of how cartels operate. For example, although the mean number of

\footnotetext{
${ }^{1}$ These 'typical' values reflect our reading of various well-known literature surveys, e.g. Levenstein and Suslow (2006), Connor (2014), De (2011). Needless to say, large variance around these means/medians is observed, with considerable discussion about some of them, most notably overcharge.

${ }^{2}$ See for example: OECD (2013), European Commission (2014), or Competition and Markets Authority (2015).
} 
cartel members for observed cartels may be 4 to 7 , we can not exclude the possibility that the 'true' mean is much smaller, say two or three, it is just that small numbers cartels are rarely observed - either because they are more successful at hiding their existence, or because they opt for tacit rather than explicit collusion in the face of punitive cartel policy, i.e. they are deterred.

Our objective in this paper is to investigate whether a key characteristic, overcharge, differs between detected and deterred cartels. We approach this both empirically and theoretically. We first explore a large historical dataset on overcharges of legal and illegal cartels (drawn from John Connor's extensive database). We suggest that legal cartels offer the best practicable, albeit imperfect, option for observing the counterfactual - what would happen in a world where there was no anti-cartel enforcement. A comparison of the distributions of overcharge for legal and illegal cartels reveals a significantly greater mass in the tails of the legal distribution. We draw the inference that this must be because the lowest and highest overcharge cartels are most likely to be deterred, and/or to go undetected where anti-cartel law and enforcement are in existence.

To distinguish between these two alternatives, we then turn to theory for guidance. We construct a theoretical model of cartel formation. Unlike previous works our emphasis is not on the conditions which facilitate cartelisation, but rather the implications for which types of cartel are more likely to be affected by deterrence. Our model predicts that there will be differential deterrence, with the very low and very high overcharge cartels most likely to be deterred.

Section 2 surveys the relevant previous literature; Sections 3 and 4 describe the data and present the empirical results; Section 5 introduces the theoretical model, and Section 6 concludes.

\section{Previous literature}

The deterrent effect of law has been the subject of academic attention following Becker's seminal work (1968) which paved the way for decades of law and economics research. More specifically on cartels, previous works have focused on different aspects of deterrence, such as the optimal type and amount of criminal sanctions. ${ }^{3}$ Recently

\footnotetext{
${ }^{3}$ See for example Elzinga and Breit (1973), Landes (1983), Kobayashi (2001), Ginsburg and Wright (2010), Werden, Hammond, and Barnett (2012), Katsoulacos and Ulph (2013), and Kat-
} 
some research has turned to experiments, attempting a more direct examination of deterrence in a controlled laboratory environment. ${ }^{4}$ However, only relatively few studies have attempted to quantify the magnitude of deterrence. Focusing specifically on the impact of leniency programmes, Miller (2009) provides a theoretical model of cartel formation over time and shows qualitatively that the introduction of the 1993 leniency programme increased the strength of deterrence. Qualitative survey studies involving interviews of competition practitioners, lawyers and companies have attempted to quantify what they refer to as deterrence multipliers. ${ }^{5}$ But none of these have posed the question raised in the current paper: 'do deterred cartels differ systematically from detected cartels'?

As mentioned above, our theoretical model in Section 5 belongs to the strand of existing literature on cartel formation in the presence of antitrust enforcement. For example, Motta and Polo (2003) assume perfectly symmetric firms with three possible strategies: not collude, collude and reveal, and collude and not reveal. They derive incentive compatibility constraints, which establish which strategies firms choose given a CA with leniency programme. Harrington and Chang (2012) also analyse cartel deterrence in the presence of a $\mathrm{CA}$ and leniency programme. The model endogenises the level of intervention by the $\mathrm{CA}$ as a function of their resources and workload. It identifies circumstances where leniency can contribute to higher/lower cartel rates. Although very relevant to our work here, none of these papers focusses explicitly on which types of cartels are most likely to be deterred. ${ }^{6}$

Empirically, our paper is based on a comparison of legal and illegal cartels. Here, some of the relevant existing literature includes Hyytinen, Steen, and Toivanen (2015) who find that the average duration of a large historical sample of Finnish legal cartels is relatively long (11.2 years in manufacturing, and 13.6 years in non-manufacturing industries). As they point out, these are greater than the average duration for illegal cartels, as reported in Levenstein and Suslow's survey of illegal cartels. Haucap, Heimeshoff, and Schultz (2010) compare the characteristics of German legal and il-

soulacos, Motchenkova, and Ulph (2015).

${ }^{4}$ For cartels specifically see Bigoni, Fridolfsson, Coq, and Spagnolo (2012).

${ }^{5}$ Office of Fair trading (2007), Office of Fair Trading (2011).

${ }^{6}$ Most models imply that enforcement will tend to reduce overcharge, although some papers suggest that this need not always be so. Harrington (2004), for instance, shows that when the expected penalty partly depends on historical prices, anti-trust enforcement may relax incentive constraints, thereby allowing the cartel to sustain a higher price. Recently, Bos and Harrington (2015) have shown that policy may lead to an increase in cartel size and price. 
legal cartels between 1958 and 2004 and find that legal cartels are more likely to last longer and to have more members than illegal cartels. Most closely related to our work are various papers using Connor's cartel dataset (2014). Typically, these include the legal/illegal dichotomy as an explanatory variable in regression analysis of the determinants of cartel overcharge. Typically, they find that the mean overcharge is not statistically different between legal and illegal cartels. (Connor and Bolotova (2006), Bolotova (2009), and Connor (2014).) Most recently, Smuda (2014) compares how various characteristics of the European cartels within Connor's dataset correlate with overcharge; although he finds that illegal cartel overcharges are marginally higher (2.59 percentage points) than legal cartel overcharges, this is not statistically significant.

\section{The database}

Our empirical work compares the distributions of overcharge between legal and illegal cartels. This is motivated by the thought that the legal distribution will reveal what the distribution would look like in a world without cartel law and enforcement. Of course, this comparison will be complicated by confounding factors, and these are discussed below. In spite of these, we believe that the distribution of legal cartels offers the most practicable option for quantifying the counterfactual.

We employ Connor's well known database in its most recent published form (2014, Appendices 1 and 2). It covers approximately 500 cartels and includes 1500 observations on episodic overcharge (many cartels had more than one episode). In effect, this is a meta-analysis of hundreds of previous studies drawn from across the world and over time. Apart from its considerable and impressive breadth, this is ideal for our purpose since it includes a sizeable number of legal cartels. These were cartels which operated in countries and time periods when cartels were not illegal, or were granted exemptions from cartel laws (notably export cartels). His published tables classify each cartel by whether it was illegal, legal or 'extra-legal'. He explains, that "Three-fourths of the cartels $(75 \%)$ were found to be in violation of antitrust laws [...] Eighteen percent of the remaining cartelized markets are known or believed to be "legal," because they operated prior to the enactment of antitrust laws in the jurisdictions in which they functioned or because they were organized and registered under antitrust exemptions, such as export cartels or ocean shipping conferences. 
About $7 \%$ of the cartels may be described as "extra-legal" because there was nothing in the case material indicating that an antitrust authority punished them" (Connor 2014, p.33).

For present purposes, we have constructed our legal sample to include all those that Connor categorises as 'legal', supplemented by a small number (ten) of his 'extralegal' category. In our readings of his extra-legal cases, most were probably illegal or sometimes not even strictly cartels at all; but in these ten cases we believe - based on available information - that the cartels were genuinely legal. ${ }^{7}$ In all, this gives us a sample of 107 legal cartels and 395 illegal. Very often cartels had more than one episode, and the measure we adopt of overcharge is the mean episodic overcharge for each cartel. Connor provides estimates of this for 390 and 1107 episodes respectively.

\section{What can we observe from data?}

Table 1 compares the two distributions. The mean is not significantly different between legal and illegal cartels; the median is slightly larger for legal cartels (a Mann Whitney test confirms that this is significant), but what is most relevant for our purposes are the greater masses in the two tails of the legal distribution. At the lower end, overcharges of $5 \%$ or less occur twice as frequently in the legal sample than in the illegal sample (21.7\% compared to $10.7 \%)$; at the upper end, overcharges of at least $50 \%$ account for nearly twice as frequently in the legal sample compared to the illegal (27.7\% versus $15.1 \%)$.

Table 1: Legal versus Illegal Cartels: Descriptive Statistics

\begin{tabular}{lcc}
\hline & Legal overcharge & Illegal overcharge \\
\hline \hline Cartels & 107 & 395 \\
Cartel episodes & 390 & 1107 \\
Mean episodic overcharge & 41.1 & 40.7 \\
Median episodic overcharge & 27.0 & 22.0 \\
Overcharge 5\% or less & $21.7 \%$ & $10.7 \%$ \\
Overcharge 5-50\% & $50.6 \%$ & $74.2 \%$ \\
Overcharge more than 50\% & $27.7 \%$ & $15.1 \%$
\end{tabular}

Figure 1, which shows the kernel density plots, provides visual confirmation that

\footnotetext{
${ }^{7}$ Our judgements are based largely on the case details provided in Connor's (2014) data Appendices, in some cases supplemented by literature searches on the specific cartels.
} 
Figure 1: Density plot of overcharge under illegal and legal regimes

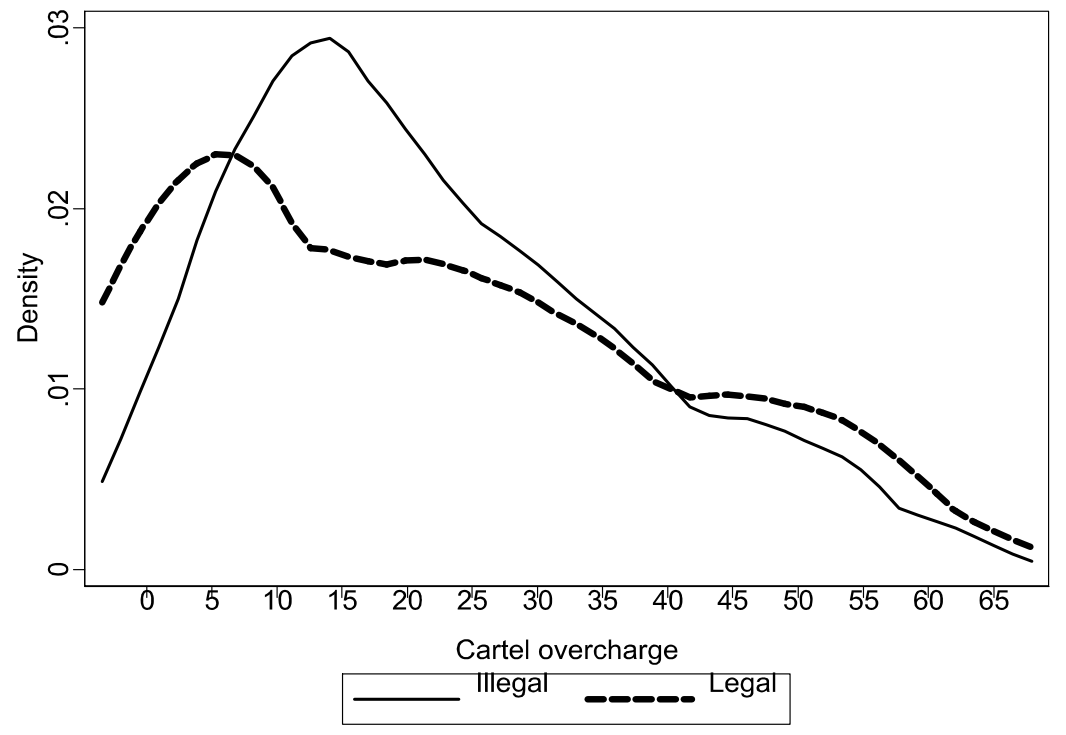

the legal distribution is more heavily populated in both tails. It also allows us to define the tails more precisely as overcharges of $<6 \%$ and $>40 \%$ respectively, (i.e. below and above the points of intersection of the two density curves).

As a test of statistical significance, a conventional Kolmogorov-Smirnov test strongly rejects the hypothesis of no difference $(\mathrm{p}=0.000)$ between the two samples. More detail is provided by a quantile regression (as discussed in Koenker and Bassett, 1978), distinguishing between legal and illegal cartels with a dummy variable. Table 2 reports the results for just the key 4 quartiles. ${ }^{8}$ As can be seen, low-overcharge cartels are significantly more frequent in legal regimes: $25 \%$ of the legal cartels overcharged by $7.5 \%$ or less, while the lowest $25 \%$ of illegal cartels overcharged by $11.7 \%$ or less. Similarly, high-overcharge cartels are strongly significantly more frequent under the legal regime: $25 \%$ of legal cartels overcharged by greater than $55 \%$, but the highest $25 \%$ of illegal cartels had overcharge in excess of $39 \%$.

\subsection{Sensitivity analysis}

These results establish a statistically significant difference between the distributions of legal and illegal cartels in Connor's database - one previously unnoticed because

\footnotetext{
${ }^{8}$ Table 3 in the Appendix reports the full results of the regression.
} 
Table 2: Illegal v legal overcharge at quartiles

\begin{tabular}{cccc}
\hline & Illegal overcharge & legal overcharge & $\mathrm{p}$ \\
\hline \hline Q1 $(25 \%)$ & 11.7 & 7.5 & 0.007 \\
Q2 $(50 \%)$ & 22 & 27 & 0.04 \\
Q3 $(75 \%)$ & 39.0 & 55.0 & 0.002
\end{tabular}

researchers have not looked beyond sample means or medians. In itself, this may be an interesting historical fact, but we wish to go further in attributing the difference to the legality or otherwise per se. In other words, we use the legal distribution as a passable approximation to the counterfactual; that is, an unbiased sample drawn from the 'as if' population of all cartels, which would be observed at all points in time across all jurisdictions, were cartels not illegal.

However, this raises the obvious question of whether other things are equal across the two sub-samples. Further examination of the 107 legal cartels reveals that 88 occurred in jurisdictions/time periods without applicable cartel law, while 13 were export cartels and 6 were other exemptions or government-tolerated. In a literal sense then, the sample is correctly defined as cases occurring where there is no applicable cartel law. However, this does not necessarily mean that all other factors are held constant when comparing the legal with the illegal distributions. Most obviously, in most jurisdictions legal prohibition of cartels only dates from the second half of the twentieth century, or later, so it is likely that more of the legal cartels occurred relatively longer ago. This is confirmed by Connor's own statistics: $70 \%$ of legal episodes occurred pre-1945, as opposed to only $13 \%$ of illegal. It is also true that the typical level of overcharge in the database as a whole has declined over time.

Therefore, as a first sensitivity test, we have re-computed the density plots and rerun the quantile regression using a restricted sample of only pre-1945 cartels. This gives 336 legal and 162 illegal episodes. While this accounts for $86 \%$ of the legal episodes, the comparison is now with only the $15 \%$ of cartels which were illegal over the same time period. The results of the quantile regression for the sample of pre1945 cartels are reported in Table 4 in the Appendix. As can be seen, results are qualitatively unchanged: significantly greater masses are observed in the tails of the legal distribution.

In a second sensitivity test, we acknowledge previous critiques of Connor's database. Although his database is remarkable in both its breadth and scale, some authors 
have previously questioned the quality of some of the estimates. ${ }^{9}$ We have therefore screened the database, now only including estimates whose primary sources were published in peer-reviewed academic journals and books. This removes over 200 observations from the sample. Again, however, results are qualitatively unchanged, as shown in Table 5 in the Appendix.

At this stage therefore, we carry forward, with the status of a robust fact, that the effect of anti-cartel policy is to reduce the frequency of relatively lower and higher overcharge cartels. At this stage, we note that this might be explained by either a greater deterrence and/or a reduced detection of such cartels. The purpose of the model below is to establish the plausibility of the deterrence explanation.

\section{A model of cartel formation}

We now formulate a theoretical model which explores how deterrence is related to the potential overcharge of the cartel. The model belongs within the genre of theoretical models of cartel formation, as described earlier in Section 2, and is coupled with key assumptions, on fines and detection, which are highly plausible. It finds that deterrence is indeed most likely at the two extremes, but for different reasons.

Consider an industry with $n \geq 2$ identical firms that produce a homogeneous product at constant marginal costs $c \geq 0 .{ }^{10}$ Firms interact for an infinite number of periods and simultaneously choose prices from $\left[c, p^{m}\right]$ in each period, where $p^{m}$ is the monopoly price. In this case, the symmetric static Nash equilibrium is such that each producer prices at marginal costs and makes zero economic profits. Monitoring is perfect and $\delta \in[0,1)$ is the common discount factor.

Alternatively, firms may collude through fixing a common price $p>c$ and sustain this agreement by means of a grim-trigger strategy. Thus, if any of the cartel members picks a price below the cartel price the cartel collapses and all revert to the static Nash equilibrium. In the following, we consider the formation of an all-inclusive cartel where each firm is assumed to receive an equal share of total industry profits: $\frac{1}{n} \cdot \pi(p) .{ }^{11}$ We make the following standard assumption on $\pi(p)$ :

\footnotetext{
${ }^{9}$ OXERA (2009), and Boyer and Kotchoni (2011).

${ }^{10}$ These assumptions are imposed for ease of exposition and do not affect the qualitative nature of the results derived below.

${ }^{11}$ As with the previous assumptions, the equal sharing rule is for ease of exposition. In case of unequal shares, it would be sufficient to focus on the firm with the smallest market share as within
} 
A1 $\pi(p)$ is twice continuously differentiable with $\frac{\partial \pi(p)}{\partial p}>0$ and $\frac{\partial^{2} \pi(p)}{\partial p^{2}}<0$ for all $p \in\left[c, p^{m}\right)$. Moreover, $\pi(c)=0$ and $\frac{\partial \pi\left(p^{m}\right)}{\partial p^{m}}=0$.

Assumption A1 basically states that collectively raising price above marginal cost is potentially profitable. Moreover, monopoly (or industry) profits are strictly concave and maximised at $p^{m} .^{12}$

If a cartel forms, then two things may happen in each period; the cartel is detected or remains undetected. For simplicity, we assume that in case of discovery conviction happens with certainty. Let the probability of being caught be captured by the function $\alpha(p)$. We make the following key assumption on $\alpha(p)$ :

A2 $\alpha(p)$ is twice continuously differentiable with $\frac{\partial \alpha(p)}{\partial p}>0$ and $\frac{\partial^{2} \alpha(p)}{\partial p^{2}} \geq 0$ for all $p \in\left[c, p^{m}\right]$. Moreover, $\alpha(c)>0$ and $\alpha\left(p^{m}\right)<1$.

Assumption A2 states that a cartel always faces a risk of being detected and convicted. The probability of being caught positively depends on the cartel price/overcharge and is increasing either at a constant or an increasing rate. There are at least two reasons why this assumption seems reasonable. First, and all else equal, higher cartel prices presumably raise more suspicion: unusually high or anomalous prices make customer complaints more likely, as is recognised in much of the cartel screening literature. Second, the cartel may need to expend more effort in sustaining higher prices (e.g., by setting up a joint sales agency to facilitate monitoring), which may make it more visible. ${ }^{13}$ Additionally, the probability of getting caught may be increasing at an increasing rate for similar reasons. On the other hand, a cartel price close to competitive levels may not be very visible and consequently raise little suspicion. Also, damages might be limited which could persuade customers against complaining. This risk may be significantly higher for prices close to monopoly levels.

the current setting that would be the firm with the tightest incentive compatibility constraint. Thus, if the smallest firm abides by the agreement then all other firms will abide too.

${ }^{12}$ Assumption A1 holds for a wide array of oligopoly models. For instance, A1 is satisfied for linear demand "textbook models" of the following form:

$$
D(p)=a-b p, \text { where } a-b c>0, \Longrightarrow \pi(p)=(p-c)(a-b p) .
$$

\footnotetext{
${ }^{13}$ These arguments can also be found in Sidak, Block, and Nold (1981), which is one of the few papers that assumes the detection probability to depend on the cartel overcharge. More recently, Harrington $(2004,2005)$ studies a dynamic model in which detection also depends on the magnitude of the price change.
} 
In case a cartel gets caught, each member can apply for leniency. For simplicity, we assume that only the first firm to self-report can obtain a leniency discount and that each has an equal probability of being the first. Specifically, each cartel member receives a penalty with probability $\frac{n-1+\theta}{n}$, where $\theta$ captures the leniency impact; $\theta=1$ means no leniency and $\theta=0$ is full leniency. ${ }^{14}$ Notice that this term is increasing in the number of participants as long as there is a leniency programme $(\theta<1)$. Clearly, the chance of being the first decreases with the number of cartel participants, all else equal.

Finally, we assume that prior to any leniency, firms face the following antitrust penalty:

$$
\frac{1}{n} \cdot[\gamma \cdot \pi(p)+F]
$$

where $\gamma>0$ is a penalty multiplier and $F>0$ is a fixed component. The antitrust penalty therefore consists of two parts, one depending on price (and therefore on overcharge) and the other independent of the price level. The variable part $\frac{1}{n} \cdot \gamma \cdot \pi(p)$ captures the fact that in many jurisdictions the penalty is positively related to the cartel price (e.g., through higher customer damages). The fixed part reflects the per se illegality of price-fixing cartels. That is, cartel members always face a cost associated with antitrust enforcement independent of the level of the cartel price. It literally may be thought of as a fixed fine, but may also capture disutility of imprisonment, reputation damages or costs of legal advice.

Under these assumptions, the collusive value of firm $i$ is defined recursively by:

$$
V_{i}(p)=\frac{1}{n} \cdot \pi(p)-\alpha(p) \cdot\left(\frac{n-1+\theta}{n}\right) \cdot \frac{1}{n} \cdot[\gamma \cdot \pi(p)+F]+\delta \cdot(1-\alpha(p)) \cdot V_{i}(p)
$$

or

$$
\begin{aligned}
V_{i}(p) & =\frac{\frac{1}{n} \cdot \pi(p)-\alpha(p) \cdot\left(\frac{n-1+\theta}{n}\right) \cdot \frac{1}{n} \cdot[\gamma \cdot \pi(p)+F]}{1-\delta(1-\alpha(p))} \\
& =\frac{1}{n} \cdot\left(\frac{\pi(p)-\alpha(p) \cdot\left(\frac{n-1+\theta}{n}\right) \cdot[\gamma \cdot \pi(p)+F]}{1-\delta(1-\alpha(p))}\right)=\frac{1}{n} \cdot V(p) .
\end{aligned}
$$

\footnotetext{
${ }^{14} \mathrm{~A}$ similar specification of the leniency programme can be found in Harrington (2008) and Bos and Harrington (2015).
} 
Note that each participant gets a fixed share of total cartel value and therefore all agree to maximise total cartel value. Following a standard prisoner's dilemma structure, each participant may at the same time have an incentive to deviate. To establish the incentive compatibility constraint (ICC), let us first consider the profit from cheating when the cartel sets a price $p>c$. Recall that the colluding firms use the grim punishment to sustain a collusive price, which implies zero economic profits in all periods following the period of defection. Under the assumption that there is still a chance of being caught when a firm cheats, optimal deviation gives:

$$
V_{i}^{d}(p)=\pi(p)-\min \left\{\alpha(p) \cdot\left(\frac{n-1+\theta}{n}\right), \theta\right\} \cdot \frac{1}{n} \cdot[\gamma \cdot \pi(p)+F] .
$$

First note that each firm has the same deviating profits. Second, and in light of the homogeneous good assumption, a cheating firm optimally picks a price below and arbitrarily close to the collusive price and satisfies market demand at that price. Third, deviating profits depend on competition policy design. Either a cheating firm applies for leniency which gives it a penalty of $\theta \cdot \frac{1}{n} \cdot[\gamma \cdot \pi(p)+F]$ (note that with full leniency $(\theta=0)$ this penalty disappears); or, the cheating firm may decide not to apply for leniency in which case the cartel is still discovered with probability $\alpha(p)$ with a corresponding expected penalty of $\alpha(p) \cdot\left(\frac{n-1+\theta}{n}\right) \cdot \frac{1}{n} \cdot[\gamma \cdot \pi(p)+F]$. What is optimal for the deviating firm therefore depends on the part $\min \left\{\alpha(p) \cdot\left(\frac{n-1+\theta}{n}\right), \theta\right\}$. If the chance of discovery is sufficiently high $\left(\theta<\alpha(p) \cdot\left(\frac{n-1+\theta}{n}\right)\right)$ it should apply for leniency. If $\theta>\alpha(p) \cdot\left(\frac{n-1+\theta}{n}\right)$, then it should hope for the best and not apply for leniency as the corresponding discount is not high enough. Finally, note that applying for leniency upon own initiative implies deviation as in this case the cartel is assumed to break down anyway. That is, if a firm feels the need to go for leniency, it might as well cheat by slightly undercutting the cartel price. ${ }^{15}$

Using both the collusive value stream $V_{i}(p)$ and the deviating value stream $V_{i}^{d}(p)$, we obtain an incentive compatibility constraint (ICC) for each firm $i$. This ICC is given by $V_{i}(p) \geq V_{i}^{d}(p)$, or:

\footnotetext{
${ }^{15}$ A more detailed description can be found in Harrington (2008) and Bos and Harrington (2015).
} 


$$
\begin{aligned}
& \frac{1}{n} \cdot\left(\frac{\pi(p)-\alpha(p) \cdot\left(\frac{n-1+\theta}{n}\right) \cdot[\gamma \cdot \pi(p)+F]}{1-\delta(1-\alpha(p))}\right) \\
\geq & \pi(p)-\min \left\{\alpha(p) \cdot\left(\frac{n-1+\theta}{n}\right), \theta\right\} \cdot \frac{1}{n} \cdot[\gamma \cdot \pi(p)+F] .
\end{aligned}
$$

Rearranging gives:

$$
\begin{aligned}
\Omega(p) \equiv & \frac{\pi(p) \cdot\left[1-(1-\delta) n-\alpha(p) \cdot\left(\left(\frac{n-1+\theta}{n}\right) \gamma+\delta n\right)\right]-\alpha(p) \cdot\left(\frac{n-1+\theta}{n}\right) \cdot F}{1-\delta(1-\alpha(p))} \\
& +\min \left\{\alpha(p) \cdot\left(\frac{n-1+\theta}{n}\right), \theta\right\} \cdot[\gamma \cdot \pi(p)+F] \\
\geq & 0 .
\end{aligned}
$$

Consequently, the cartel's problem is as follows:

$$
\max _{p} V(p)=\frac{\pi(p)-\alpha(p) \cdot\left(\frac{n-1+\theta}{n}\right) \cdot[\gamma \cdot \pi(p)+F]}{1-\delta(1-\alpha(p))}
$$

subject to

$$
\Omega(p) \geq 0
$$

Let $p^{*}$ indicate the solution to (1). Moreover, let $p^{\circ}=\arg \max V(p)$ be the optimal cartel price.

Before analysing the impact of antitrust enforcement on the cartel price and overcharge, it is instructive to first briefly examine what the model looks like without antitrust policy. With no anti-cartel enforcement (i.e., $\alpha(\cdot)=0$ ), the cartel's problem as given by (1) reduces to

$$
\max _{p} V(p)=\frac{\pi(p)}{1-\delta}
$$

subject to

$$
\frac{\frac{1}{n} \cdot \pi(p)}{1-\delta}-\pi(p) \geq 0 \Longrightarrow \pi(p) \cdot\left[\frac{\frac{1}{n}-1+\delta}{1-\delta}\right] \geq 0 .
$$

Observe that the ICC is satisfied for $p=c$ and that sustainability of a price $p>c$ 
requires the familiar condition $\delta \geq 1-\frac{1}{n}$ to hold. That is, for a given number of firms, the discount factor must be sufficiently close to one.

Let us now turn to assessing the impact of antitrust enforcement on the cartel price. To begin, it is clear that when anti-cartel enforcement is sufficiently strong no cartel will emerge. In the following, our focus is on situations where cartel formation is not completely deterred, which requires $\delta$ to be sufficiently high and $\alpha(\cdot)$ to be sufficiently low.

\subsection{The Lower Tail}

Independent of whether some collusion is viable, the next two results reveal that we should not expect small overcharges in a world with antitrust enforcement.

Proposition $1 \exists p^{\prime}>c$ such that $V(p)<0$ for all $p \in\left[c, p^{\prime}\right)$.

Proof. Suppose that the cartel prices at $c$. In this case, the total collusive value would be given by:

$$
V(c)=\frac{\pi(c)-\alpha(c) \cdot\left(\frac{n-1+\theta}{n}\right) \cdot[\gamma \cdot \pi(c)+F]}{1-\delta(1-\alpha(c))},
$$

which by A1 reduces to

$$
V(c)=\frac{-\alpha(c) \cdot\left(\frac{n-1+\theta}{n}\right) \cdot F}{1-\delta(1-\alpha(c))} .
$$

As $F>0$ and $\alpha(c)>0$ by A2, we conclude $V(c)<0$. Finally, as $V(p)$ is continuous in price, it will be negative for all prices sufficiently close to $c$.

The next result follows immediately:

Corollary $2 \exists p^{\prime}>c$ such that $\Omega(p)<0$ for all $p \in\left[c, p^{\prime}\right)$.

Proof. $\Omega(p)$ is given by:

$$
\begin{aligned}
& \frac{\pi(p) \cdot\left[1-(1-\delta) n-\alpha(p) \cdot\left(\left(\frac{n-1+\theta}{n}\right) \gamma+\delta n\right)\right]-\alpha(p) \cdot\left(\frac{n-1+\theta}{n}\right) \cdot F}{1-\delta(1-\alpha(p))} \\
& +\min \left\{\alpha(p) \cdot\left(\frac{n-1+\theta}{n}\right), \theta\right\} \cdot[\gamma \cdot \pi(p)+F] .
\end{aligned}
$$


By A1, $\pi(c)=0$ and therefore

$$
\Omega(c)=\frac{-\alpha(c) \cdot\left(\frac{n-1+\theta}{n}\right) \cdot F}{1-\delta(1-\alpha(c))}+\min \left\{\alpha(c) \cdot\left(\frac{n-1+\theta}{n}\right), \theta\right\} \cdot F .
$$

Rearranging gives:

$$
\Omega(c)=\frac{-\alpha(c) \cdot\left(\frac{n-1+\theta}{n}\right) \cdot F+\min \left\{\alpha(c) \cdot\left(\frac{n-1+\theta}{n}\right), \theta\right\} \cdot F \cdot(1-\delta(1-\alpha(c)))}{1-\delta(1-\alpha(c))}<0 .
$$

We conclude that a collusive price at marginal cost is not sustainable. By continuity, this too holds for each price above but sufficiently close to $c$.

These findings have the following simple, yet powerful, intuition. Without anticartel enforcement, all prices that weakly exceed costs could be sustained for a large enough discount factor. Some cartels may have fairly small price-cost margins for either of two reasons. First, the cartel may for some reason price below the profitmaximising monopoly price, i.e., the cartel may price suboptimally. Second, the cartel sets the profit-maximising monopoly price, but demand is fairly elastic so that the difference between the monopoly price and unit costs is limited. Either way, these cartels will earn limited profits. The above findings show that these cartels become unprofitable (and therefore unsustainable) with antitrust enforcement, which is due to the fixed penalty that results from acting in breach of the law. That is, for the simple reason that explicit collusion is illegal and costly in expected terms, anti-cartel enforcement will deter cartels with a too small overcharge.

\subsection{The Upper Tail}

As mentioned above, without antitrust enforcement the collusive value is maximised by charging the monopoly price. As the next result shows, the price that maximises total cartel value lies strictly below the monopoly price with antitrust enforcement.

Proposition 3 In the presence of an antitrust authority, $p^{\circ}<p^{m}$.

Proof. First note that the statement is vacuously true when collusion is not viable. Therefore, suppose that antitrust enforcement is not too strong so that some collusion on a price $p>c$ is feasible. 
To begin, let us evaluate the value function $V(p)$. The first and second order derivative with respect to price are respectively given by:

$$
\begin{aligned}
& \frac{\partial V(p)}{\partial p}= \\
& \left\{\begin{array}{c}
{[1-\delta(1-\alpha(p))] \cdot} \\
{\left[\frac{\partial \pi(p)}{\partial p}-\left(\frac{n-1+\theta}{n}\right) \cdot\left(\frac{\partial \alpha(p)}{\partial p} \cdot[\gamma \cdot \pi(p)+F]+\alpha(p) \cdot \gamma \frac{\partial \pi(p)}{\partial p}\right)\right]} \\
-\left[\pi(p)-\alpha(p) \cdot\left(\frac{n-1+\theta}{n}\right) \cdot[\gamma \cdot \pi(p)+F]\right] \cdot \\
{\left[\delta \cdot \frac{\partial \alpha(p)}{\partial p}\right]}
\end{array}\right\} \cdot[1-\delta(1-\alpha(p))]^{-2} \\
& =\frac{\frac{\partial \pi(p)}{\partial p} \cdot\left[1-\alpha(p)\left(\frac{n-1+\theta}{n}\right) \gamma\right]-\frac{\partial \alpha(p)}{\partial p} \cdot\left[\left(\frac{n-1+\theta}{n}\right) \cdot[\gamma \pi(p)+F]+\delta V(p)\right]}{1-\delta(1-\alpha(p))} \text {, }
\end{aligned}
$$

and

$$
\begin{aligned}
& \frac{\partial^{2} V(p)}{\partial p^{2}}= \\
& \left\{\begin{array}{c}
{[1-\delta(1-\alpha(p))] \cdot} \\
{\left[\begin{array}{c}
\frac{\partial^{2} \pi(p)}{\partial p^{2}} \cdot\left[1-\alpha(p)\left(\frac{n-1+\theta}{n}\right) \gamma\right] \\
-\frac{\partial^{2} \alpha(p)}{\partial p^{2}} \cdot\left[\left(\frac{n-1+\theta}{n}\right)(\gamma \pi(p)+F)+\delta V(p)\right] \\
-\frac{\partial \alpha(p)}{\partial p} \cdot\left[2\left(\frac{n-1+\theta}{n}\right) \gamma \frac{\partial \pi(p)}{\partial p}+\delta \frac{\partial V(p)}{\partial p}\right]
\end{array}\right]} \\
-\left[\begin{array}{c}
\frac{\partial \pi(p)}{\partial p} \cdot\left(1-\alpha(p)\left(\frac{n-1+\theta}{n}\right) \gamma\right) \\
-\frac{\partial \alpha(p)}{\partial p} \cdot\left[\left(\frac{n-1+\theta}{n}\right) \cdot[\gamma \pi(p)+F]+\delta V(p)\right]
\end{array}\right] \cdot\left[\delta \cdot \frac{\partial \alpha(p)}{\partial p}\right]
\end{array}\right\} \cdot[1-\delta(1-\alpha(p))]^{-2} \\
& =\left\{\begin{array}{c}
\frac{\partial^{2} \pi(p)}{\partial p^{2}}\left[1-\alpha(p)\left(\frac{n-1+\theta}{n}\right) \gamma\right]- \\
\frac{\partial^{2} \alpha(p)}{\partial p^{2}}\left[\left(\frac{n-1+\theta}{n}\right)(\gamma \pi(p)+F)+\delta V(p)\right]- \\
2 \frac{\partial \alpha(p)}{\partial p}\left[\left(\frac{n-1+\theta}{n}\right) \gamma \frac{\partial \pi(p)}{\partial p}+\delta \frac{\partial V(p)}{\partial p}\right]
\end{array}\right\} \cdot[1-\delta(1-\alpha(p))]^{-1}
\end{aligned}
$$

Concentrating on the second-order derivative first, notice that $V(p)>0$ requires 1 $\alpha(p)\left(\frac{n-1+\theta}{n}\right) \gamma>0$ so that the first term is strictly negative by A1. The second term is weakly positive by A2. Finally, the sign of the third term is ambiguous. Observe, however, that the third term is weakly positive when $\frac{\partial V(p)}{\partial p}=0$. Consequently, the second order derivative is strictly negative at stationary points. $V(p)$ then has a unique maximum that is given by the first order condition:

$$
\frac{\frac{\partial \pi(p)}{\partial p} \cdot\left[1-\alpha(p)\left(\frac{n-1+\theta}{n}\right) \gamma\right]-\frac{\partial \alpha(p)}{\partial p} \cdot\left[\left(\frac{n-1+\theta}{n}\right) \cdot[\gamma \pi(p)+F]+\delta V(p)\right]}{1-\delta(1-\alpha(p))}=0 .
$$


Rearranging gives:

$$
\frac{\partial \pi(p)}{\partial p}=\frac{\frac{\partial \alpha(p)}{\partial p} \cdot\left[\left(\frac{n-1+\theta}{n}\right) \cdot[\gamma \pi(p)+F]+\delta V(p)\right]}{1-\alpha(p)\left(\frac{n-1+\theta}{n}\right) \gamma}
$$

Note that the RHS is strictly positive by A2, whereas $\frac{\partial \pi\left(p^{m}\right)}{\partial p^{m}}=0$. As $\frac{\partial \pi(p)}{\partial p}>0$ and $\pi(p)$ is strictly concave by A1, we conclude that $p^{\circ}<p^{m}$ in the presence of an antitrust authority.

In a world without antitrust enforcement, the optimal cartel price is the monopoly price. In a world with antitrust enforcement, the optimal cartel price is bounded below the monopoly price. This result is essentially driven by the fact that anticartel enforcement makes the marginal expected antitrust penalty positive. If the penalty would be insensitive to the cartel price, then, just like in a world without antitrust enforcement, these 'marginal cost of colluding' would be zero. In that case, the optimal cartel price would be the monopoly price as that is the price for which marginal profit equals zero. As the penalty depends on price, the marginal expected penalty is greater than zero and therefore the optimal cartel price lies below the monopoly price. It is noteworthy that this finding seems to be very robust. A comparable result has been obtained in a static model (Sidak, Block and Nold, 1981) and a structural dynamic model (Harrington, 2005).

The above result provides a rationale for why we should expect the highest overcharges to be lower in the presence of an antitrust authority (composition deterrence). Yet, antitrust enforcement not only reduces the optimal cartel price, but also affects the ICC. In particular, one can imagine that the expected penalty is so sensitive to the price level that the cartel is willing to set $p^{\circ}$ but that it is unable to sustain this price in which case $p^{*}<p^{\circ}$.

To further explore this possibility, observe that when $\theta<\alpha(p) \cdot\left(\frac{n-1+\theta}{n}\right)$,

$$
\begin{aligned}
& \frac{\partial^{2} \Omega(p)}{\partial p^{2}}= \\
& \left\{\begin{array}{c}
\frac{\partial^{2} \pi(p)}{\partial p^{2}} \cdot\left[\begin{array}{c}
\left.1-\alpha(p)\left(\frac{n-1+\theta}{n}\right) \gamma-(n-\theta \gamma)(1-\delta(1-\alpha(p)))\right]- \\
\frac{\partial^{2} \alpha(p)}{\partial p^{2}} \cdot\left[\left(\frac{n-1+\theta}{n}\right)(\gamma \pi(p)+F)+\delta V(p)\right]- \\
2 \frac{\partial \alpha(p)}{\partial p} \cdot\left[\left(\frac{n-1+\theta}{n}\right) \gamma \frac{\partial \pi(p)}{\partial p}+\delta\left(\frac{\partial \Omega}{\partial p}+n \frac{\partial V_{i}^{d}(p)}{\partial p}\right)\right]
\end{array}\right\} \cdot[(1-\delta(1-\alpha(p))) n]^{-1}
\end{array}\right\} \cdot\left[\begin{array}{l} 
\\
2
\end{array}\right.
\end{aligned}
$$


and when $\theta>\alpha(p) \cdot\left(\frac{n-1+\theta}{n}\right)$,

$$
\begin{aligned}
& \frac{\partial^{2} \Omega(p)}{\partial p^{2}}= \\
& \left\{\begin{array}{c}
\frac{\partial^{2} \pi(p)}{\partial p^{2}} \cdot\left[1-\alpha(p)\left(\frac{n-1+\theta}{n}\right) \gamma-\left(n-\alpha(p)\left(\frac{n-1+\theta}{n}\right) \gamma\right)(1-\delta(1-\alpha(p)))\right]- \\
\frac{\partial^{2} \alpha(p)}{\partial p^{2}} \delta \cdot\left[\left(\frac{n-1+\theta}{n}\right)(\gamma \pi(p)+F)(1-\alpha(p))+V(p)\right]- \\
2 \frac{\partial \alpha(p)}{\partial p} \delta \cdot\left[\left(\frac{n-1+\theta}{n}\right) \gamma \frac{\partial \pi(p)}{\partial p}(1-\alpha(p))+\left(\frac{\partial \Omega}{\partial p}+n \frac{\partial V_{i}^{d}(p)}{\partial p}\right)\right]
\end{array}\right\} \\
& \cdot[(1-\delta(1-\alpha(p))) n]^{-1} .
\end{aligned}
$$

Though the sign of the second-order derivatives is not a priori clear, both are strictly negative at $\frac{\partial \Omega}{\partial p}=0$ provided that collusion is sustainable. Thus, $\Omega(p)$ has a maximum that moreover is reached at a price below $p^{\circ} .{ }^{16}$ This suggests it might be possible that the maximal sustainable cartel price is not only below $p^{m}$, but even below $p^{\circ}$ (i.e., $p^{*}<$ $p^{\circ}$. That is, it seems that AE may make the ICC binding under certain conditions. Note that this would enhance the above result in that the highest overcharges are deterred with antitrust enforcement. ${ }^{17}$

Whether the ICC is indeed binding critically depends on the precise parameter values. However, as the next example illustrates, this possibility is real.

Example 4 (1) Suppose that:

$$
\begin{aligned}
& n=2 \\
& \theta=0 \\
& \gamma=2 \\
& c=0 \\
& \pi(p)=p(1-p) \\
& \delta=\frac{6}{10} \\
& \alpha(p)=p+x \quad \text { (with } x \in\left(0, \frac{1}{2}\right) \text { by A2) }
\end{aligned}
$$

Note that absent antitrust enforcement, the optimal cartel price would be $p^{m}=\frac{1}{2}$ and that this cartel price would be sustainable as $\delta=\frac{6}{10} \geq 1-\frac{1}{n}=\frac{1}{2}$.

\footnotetext{
${ }^{16}$ This is so as $\frac{\partial \Omega(p)}{\partial p}=0$ implies $\frac{\partial V(p)}{\partial p}=\frac{\partial V^{d}(p)}{\partial p}$, whereas $\frac{\partial V\left(p^{\circ}\right)}{\partial p^{\circ}}=0$ and $\frac{\partial V^{d}\left(p^{\circ}\right)}{\partial p^{\circ}}>0$.

${ }^{17}$ Even though this may sound intuitive, it is noteworthy that there are conditions under which antitrust may in fact loosen the ICC, thereby allowing for higher cartel prices. See Harrington (2004).
} 
With antitrust enforcement, the optimal cartel price is given by:

$$
\frac{\partial V(p)}{\partial p}=\frac{\frac{\partial \pi(p)}{\partial p} \cdot\left[1-\alpha(p)\left(\frac{n-1+\theta}{n}\right) \gamma\right]-\frac{\partial \alpha(p)}{\partial p} \cdot\left[\left(\frac{n-1+\theta}{n}\right) \cdot[\gamma \pi(p)+F]+\delta V(p)\right]}{1-\delta(1-\alpha(p))}=0
$$

Using the above values this gives:

$$
\begin{aligned}
& \frac{\partial \pi(p)}{\partial p} \cdot\left[1-\alpha(p)\left(\frac{n-1+\theta}{n}\right) \gamma\right]-\frac{\partial \alpha(p)}{\partial p} \cdot\left[\left(\frac{n-1+\theta}{n}\right) \cdot[\gamma \pi(p)+F]+\delta V(p)\right]=0, \\
& (1-2 p) \cdot[1-(p+x)]-p(1-p)-\frac{1}{2} \cdot F-\frac{6}{10} \cdot V(p)=0, \\
& (1-2 p) \cdot[1-(p+x)]-p(1-p)-\frac{1}{2} \cdot F-\left(\frac{p(1-p)-(p+x) \cdot p(1-p)-\frac{1}{2}(p+x) F}{\frac{2}{3}+(p+x)}\right)=0 \text {. }
\end{aligned}
$$

Now suppose that $x \simeq 0$ and $F \simeq 0$. This gives

$$
\begin{aligned}
(1-2 p) \cdot(1-p)-p(1-p)-\left(\frac{p(1-p)-p^{2}(1-p)}{\frac{2}{3}+p}\right) & =0 \\
1-3 p-\left(\frac{p(1-p)}{\frac{2}{3}+p}\right) & =0 \\
-p^{2}-p+\frac{1}{3} & =0 \\
p & =\frac{1 \pm \sqrt{2 \frac{1}{3}}}{-2} .
\end{aligned}
$$

Thus, $p^{\circ} \simeq 0,264$, which is indeed below the monopoly price $p^{m}=\frac{1}{2}$ as established by Proposition 3 above.

Next, we will show that the optimal cartel price $p^{\circ} \simeq 0,264$ is not sustainable. The per-firm collusive value is approximately equal to

$$
V_{i}^{c}\left(p^{\circ}\right)=\frac{1}{2} \cdot\left(\frac{p^{\circ}\left(1-p^{\circ}\right)-\left(p^{\circ}\right)^{2}\left(1-p^{\circ}\right)}{\frac{4}{10}+\frac{6}{10} p^{\circ}}\right) \simeq \frac{1}{2} \cdot\left(\frac{0,194-0,0513}{0,5584}\right) \simeq 0,128,
$$

whereas deviating from $p^{\circ}$ approximately yields

$$
V_{i}^{d}\left(p^{\circ}\right)=p^{\circ}\left(1-p^{\circ}\right) \simeq 0,194
$$

Thus, the optimal cartel price $p^{\circ}$ cannot be sustained. 
It remains to be shown that there is a lower supracompetitive price that is sustainable. Such a price does indeed exist. For instance, with $p=0.05$ the per-firm collusive value is approximately equal to

$$
V_{i}^{c}(p)=\frac{1}{2} \cdot\left(\frac{p(1-p)-p^{2}(1-p)}{\frac{4}{10}+\frac{6}{10} p}\right)=\frac{1}{2} \cdot\left(\frac{0,0475-0,002375}{0,43}\right) \simeq 0,05247
$$

whereas deviating from $p=0,05$ yields

$$
V_{i}^{d}(p)=p(1-p)=0,0475
$$

In fact, for the given parameter values the ICC has three roots at $p=0, p=\frac{1}{11}$ and $p=1$. Consequently, the optimal cartel price is $p=\frac{1}{11}$. Antitrust enforcement therefore not only reduces the optimal cartel price, but may additionally tighten the $I C C$, thereby forcing cartels to reduce price even further.

\subsection{Implications}

In sum, the above analysis provides a deterrence rationale for our empirical observations. Anti-cartel enforcement deters low overcharge cartels by making such agreements unprofitable in expected terms and therefore unsustainable. High overcharge cartels are also deterred, but in a different way and for a different reason. First, when the expected antitrust penalty is sensitive to the price level, anti-cartel enforcement reduces the optimal cartel price. Second, it may tighten the ICC in such a way that the maximal sustainable cartel price is below the profit-maximising level. In both these effects, it is the cartels with the highest overcharges that are deterred. Note, however, that this does not mean that these firms will not collude. Rather, they collude on a lower cartel price in comparison to a world without anti-cartel enforcement. Thus, in a world with a less than fully deterrent antitrust system, one should expect cartels with moderate, rather than low or high overcharges.

This prediction is clearly consistent with our empirical findings, but is there an alternative explanation in terms of lower detection rates in the tails? Clearly this is precluded in the above model for the upper tail by the assumption that the probability of detection increases with price. Similarly, if the probability of detection were invariant with respect to overcharge, then this would rule out the possibility of lower detection in the tails. 
Only in the unlikely event that the probability of detection decreases with price, could the model provide a non-detection explanation: in that case, it would predict that cartels will raise price, even above the monopoly level. This would leave fewer low price cartels and, at the top end, fewer high price cartels would be detected. However, such an assumption would not fit with either intuition or with previous works. Indeed, the possibility that the CA would devote fewer resources to detecting high price cartels seems entirely implausible.

\section{Conclusion}

The empirical contribution of this paper derives from a novel comparison of the distributions of overcharge observed for cartels between jurisdictions which did and did not prohibit cartels. It shows that the distribution for legal cartels has significantly more mass in its tails than does the distribution for illegal cartels. This finding is robust to controlling for the time period in which the cartels occurred and the perceived quality of the sources of the data. We suggest it has two potential explanations, not necessarily mutually exclusive. It may be that anti-cartel law is most effective in deterring very low or very high overcharge cartels, or it may be that such cartels are least likely to be detected in a world where cartels are illegal.

The remainder of the paper is designed to distinguish which of these potential explanations is more likely. To do this, we present a fairly general theoretical model which is representative of the previous literature on cartel formation. This establishes the conditions under which we can deduce that its is deterrence which drives the empirical result. We argue that only relatively weak assumptions are required: in essence, low-overcharge cases are deterred by fines which have (at least partly) a fixed element, while high-overcharge cases, in the face of a higher probability of detection, either moderate their overcharge to lessen the likelihood of detection and lower the expected penalty (composition deterrence), or entirely abandon the cartel (frequency deterrence) because incentives become incompatible.

This has some potentially important implications. In the previous literature, evidence on the nature of detected cartels has been widely used as a key source of information about the nature of collusion in the real world. But it now needs to be underlined that this evidence emanates only from cases which are not deterred, and are detected, by active anti-cartel enforcement policy. In that this ignores cases 
which are deterred, it may seriously underestimate the welfare-enhancing impact of policy, especially insofar as it is the most harmful cases which are most likely to be deterred. ${ }^{18}$ This also raises doubts about conventional empirical wisdoms on the structural factors which are conducive to collusion. The evidence of this paper is confined to overcharge, but it is not unlikely that overcharge will be related to the structure of the cartel (number and asymmetries of members, duration, etc). If so evidence from previous studies on the structure and stability of cartels may require revisiting.

Future work with cartel overcharge data might be used to make inferences on how the level of deterrence varies over time or across geographic areas. For example in comparing cartel overcharges across two jurisdictions, the relative weight of the tails of the overcharge distribution could help us establish which jurisdictions has higher/lower deterrence and help determine what type of anti-cartel policy is more effective.

\section{References}

Becker, G. S. (1968): "Crime and Punishment: An Economic Approach," The Journal of Political Economy, 76(2), 169-217.

Bigoni, M., S.-O. Fridolfsson, C. L. Coq, and G. Spagnolo (2012): "Fines, Rewards, and Leniency in Antitrust," RAND Journal of Economics, 43(2), 368390.

Bolotova, Y. V. (2009): "Cartel overcharges: An empirical analysis," Journal of Economic Behavior and Organization, 70(1).

Bos, I., And J. E. Harrington (2015): "Competition Policy and Cartel Size," International Economic Review, 56(1), 133-153.

Boyer, M., and R. Kotchoni (2011): "The econometrics of cartel overcharges," CIRANO-Scientific Publication, 2011.

Competition And Markets Authority (2015): "CMA Impact Assessment," .

\footnotetext{
${ }^{18}$ Davies and Ormosi (2014) designed a framework for using the information on the tails in order to calibrate the relative magnitude of deterred and undetected cartel harm.
} 
Connor, J. M. (2014): "Price-Fixing Overcharges: Revised 3rd Edition," Available at SSRN: http://ssrn.com/abstract=2400780.

Connor, J. M., and Y. Bolotova (2006): "Cartel Overcharges: Survey and MetaAnalysis," International Journal of Industrial Organization, 24(6), 1109-1137.

Davies, S. W., and P. L. Ormosi (2014): "The Economic Impact of Cartels and Anti-Cartel Enforcement," CCP Working Paper 13-\%.

DE, O. (2011): "Analysis of cartel duration: Evidence from ec prosecuted cartels," International Journal of the Economics of Business, 17(1), 33-65.

Elzinga, K. G., And W. Breit (1973): "Antitrust Penalties and Attitudes Toward Risk: An Economic Analysis," Harvard Law Review, 86, 693.

European Commission (2014): "Annual Activity Report," European Commission, DG Competition.

Ginsburg, D. H., And J. D. Wright (2010): “Antitrust Sanctions," Competition Policy International, 6(2), 3-39.

Harrington, J. E. (2004): "Cartel Pricing Dynamics in the Presence of an Antitrust Authority," The RAND Journal of Economics, 35(4), 651-673.

- (2005): "Optimal Cartel Pricing in the Presence of an Antitrust Authority," International Economic Review, 46(1), 145-169.

- (2008): "Optimal Corporate Leniency Programs," The Journal of Industrial Economics, 56(2), 215-246.

Harrington, J. E., And M.-H. Chang (2012): "Endogenous Antitrust Enforcement in the Presence of a Corporate Leniency Program," Working Paper.

Haucap, J., U. Heimeshoff, and L. M. Schultz (2010): "Legal and illegal cartels in Germany between 1958 and 2004," DICE discussion paper, 2010(8).

Hyytinen, A., F. Steen, and O. Toivanen (2015): "Anatomy of cartel contracts," NHH Dept. of Economics Discussion Paper, 2015(25). 
Katsoulacos, Y., E. Motchenkova, and D. Ulph (2015): "Penalizing cartels: The case for basing penalties on price overcharge," International Journal of Industrial Organization, 42, 70-80.

Katsoulacos, Y., and D. Ulph (2013): "Antitrust Penalties and the Implications of Empirical Evidence on Cartel Overcharges," Economic Journal, 123.

Kobayashi, B. H. (2001): "Antitrust, Agency, and Amnesty: An Economic Analysis of the Criminal Enforcement of the Antitrust Laws," George Washington Law Review, 715, 735-739.

Koenker, R., and G. Bassett (1978): "Regression Quantiles," Econometrica, 46(1), 33-50.

Landes, W. M. (1983): "Optimal Sanctions for Antitrust Violations," University of Chicago Law Review, 50, 652.

Levenstein, M. C., And V. Y. Suslow (2006): "What determines cartel success?," Journal of Economic Literature, pp. 43-95.

Miller, N. H. (2009): "Strategic Leniency and Cartel Enforcement," American Economic Review, 99(3), 750-768.

Motta, M., and M. Polo (2003): "Leniency Programs and Cartel Prosecution," International Journal of Industrial Organization, 21, 347-379.

OECD (2013): "Assessment of the Impact of Competition Authorities' Activities," $D A F / C O M P / W P 2(2013) 1$.

Office of Fair trading (2007): "The Deterrent Effect of Competition Enforcement by the OFT," A report prepared for the OFT by Deloitte, OFT962.

Office of Fair Trading (2011): "The Impact of Competition Interventions on Compliance and Deterrence," A report prepared for the OFT by London Economics, OFT1391.

OXERA (2009): "Quantifying antitrust damages: Towards non-binding guidance for courts," . 
Sidak, G., M. K. Block, And F. C. Nold (1981): "The Deterrent Effect of Antitrust Enforcement," Journal of Political Economy, 89(3), 429-445.

SmudA, F. (2014): "Cartel Overcharges and the Deterrent Effect of EU Competition Law," Journal of Competition Law and Economics, 10(1), 63.

Werden, G. J., S. D. Hammond, and B. A. Barnett (2012): "Deterrence and Detection of Cartels: Using All the Tools and Sanctions," Antitrust Bulletin, 56(2).

\section{Appendix}

\section{A Additional tables}

Table 3: Legal and illegal overcharges at different quantiles - Full sample, N=1497

\begin{tabular}{lrrrrr}
\hline & Legal & Illegal & Std. Err. & $\mathrm{t}$ & $\mathrm{P}>\mathrm{t}$ \\
\hline \hline q5 & 0 & 1.6 & 1.01 & -1.59 & 0.113 \\
q10*** & $\mathbf{0}$ & $\mathbf{5}$ & $\mathbf{0 . 4 6}$ & $\mathbf{- 1 0 . 9 2}$ & $\mathbf{0}$ \\
q15*** & $\mathbf{1}$ & $\mathbf{8 . 2}$ & $\mathbf{0 . 7 6}$ & $\mathbf{- 9 . 5 3}$ & $\mathbf{0}$ \\
q20*** & $\mathbf{4}$ & $\mathbf{1 0}$ & $\mathbf{1 . 5 1}$ & $\mathbf{- 3 . 9 7}$ & $\mathbf{0}$ \\
q25*** & $\mathbf{7 . 5}$ & $\mathbf{1 1 . 7}$ & $\mathbf{1 . 5 5}$ & $\mathbf{- 2 . 7 1}$ & $\mathbf{0 . 0 0 7}$ \\
q30* & $\mathbf{1 0 . 5}$ & $\mathbf{1 3 . 3}$ & $\mathbf{1 . 6 5}$ & $\mathbf{- 1 . 7}$ & $\mathbf{0 . 0 9}$ \\
q35 & 13.8 & 15.3 & 1.58 & -0.95 & 0.343 \\
q40 & 17 & 17.3 & 1.93 & -0.16 & 0.876 \\
q45 & 20.5 & 19.6 & 2.54 & 0.35 & 0.723 \\
q50** & $\mathbf{2 7}$ & $\mathbf{2 2}$ & $\mathbf{2 . 4 4}$ & $\mathbf{2 . 0 5}$ & $\mathbf{0 . 0 4}$ \\
q55*** & $\mathbf{3 0}$ & $\mathbf{2 4 . 8}$ & $\mathbf{1 . 6 0}$ & $\mathbf{3 . 2 4}$ & $\mathbf{0 . 0 0 1}$ \\
q60** & $\mathbf{3 4}$ & $\mathbf{2 7 . 5}$ & $\mathbf{3 . 1 9}$ & $\mathbf{2 . 0 4}$ & $\mathbf{0 . 0 4 2}$ \\
q65** & $\mathbf{4 0}$ & $\mathbf{3 0 . 5}$ & $\mathbf{4 . 0 0}$ & $\mathbf{2 . 3 7}$ & $\mathbf{0 . 0 1 8}$ \\
q70*** & $\mathbf{5 0}$ & $\mathbf{3 4}$ & $\mathbf{3 . 3 5}$ & $\mathbf{4 . 7 7}$ & $\mathbf{0}$ \\
q75*** & $\mathbf{5 5}$ & $\mathbf{3 9}$ & $\mathbf{5 . 0 4}$ & $\mathbf{3 . 1 7}$ & $\mathbf{0 . 0 0 2}$ \\
q80*** & $\mathbf{6 9}$ & $\mathbf{4 4 . 6}$ & $\mathbf{5 . 5 7}$ & $\mathbf{4 . 3 8}$ & $\mathbf{0}$ \\
q85*** & $\mathbf{9 4 . 7}$ & $\mathbf{5 0 . 7}$ & $\mathbf{1 1 . 8 6}$ & $\mathbf{3 . 7 1}$ & $\mathbf{0}$ \\
q90*** & $\mathbf{1 4 7}$ & $\mathbf{6 5 . 2}$ & $\mathbf{3 0 . 3 6}$ & $\mathbf{2 . 6 9}$ & $\mathbf{0 . 0 0 7}$ \\
q95*** & $\mathbf{2 5 4}$ & $\mathbf{1 0 0}$ & $\mathbf{4 8 . 5 3}$ & $\mathbf{3 . 1 7}$ & $\mathbf{0 . 0 0 2}$ \\
$* * *, * *$, & and $*$ denote significance in the difference be- \\
tween legal and illegal overcharge at the 99,95, and 90 \\
percent level. & \multicolumn{3}{|c}{} &
\end{tabular}


Table 4: Legal and illegal overcharges at different quantiles - Pre1945 sample, N=498

\begin{tabular}{lrrrrr}
\hline & Legal & Illegal & Std. Err. & $\mathrm{t}$ & $\mathrm{P}>\mathrm{t}$ \\
\hline \hline q05 & 0 & 0 & 1.54 & 0 & 1 \\
q10*** & $\mathbf{0}$ & $\mathbf{5}$ & $\mathbf{1 . 6 8}$ & $\mathbf{- 2 . 9 8}$ & $\mathbf{0 . 0 0 3}$ \\
q15*** & $\mathbf{1}$ & $\mathbf{7 . 2}$ & $\mathbf{1 . 6 7}$ & $\mathbf{- 3 . 7 2}$ & $\mathbf{0}$ \\
q20* & $\mathbf{5 . 3}$ & $\mathbf{9 . 2}$ & $\mathbf{2 . 4 2}$ & $\mathbf{- 1 . 6 9}$ & $\mathbf{0 . 1}$ \\
q25 & 8.7 & 11.9 & 2.37 & -1.35 & 0.177 \\
q30 & 12 & 12.4 & 3.01 & -0.13 & 0.894 \\
q35 & 15.5 & 17.2 & 3.86 & -0.44 & 0.66 \\
q40 & 20 & 21.4 & 3.77 & -0.37 & 0.711 \\
q45 & 25.5 & 24.4 & 3.97 & 0.28 & 0.782 \\
q50 & 29 & 26 & 3.51 & 0.85 & 0.393 \\
q55 & 31 & 31.6 & 4.34 & -0.14 & 0.89 \\
q60 & 38 & 35 & 4.57 & 0.66 & 0.512 \\
q65* & $\mathbf{4 6}$ & $\mathbf{3 8}$ & $\mathbf{4 . 1 6}$ & $\mathbf{1 . 9 3}$ & $\mathbf{0 . 0 5 5}$ \\
q70* & $\mathbf{5 0 . 5}$ & $\mathbf{4 2}$ & $\mathbf{4 . 3 2}$ & $\mathbf{1 . 9 7}$ & $\mathbf{0 . 0 5}$ \\
q75* & $\mathbf{6 0 . 6}$ & $\mathbf{5 0}$ & $\mathbf{6 . 2 7}$ & $\mathbf{1 . 6 9}$ & $\mathbf{0 . 0 9 1}$ \\
q80*** & $\mathbf{7 3}$ & $\mathbf{5 0}$ & $\mathbf{7 . 0 9}$ & $\mathbf{3 . 2 5}$ & $\mathbf{0 . 0 0 1}$ \\
q85*** & $\mathbf{1 0 0}$ & $\mathbf{5 5}$ & $\mathbf{1 5 . 4 5}$ & $\mathbf{2 . 9 1}$ & $\mathbf{0 . 0 0 4}$ \\
q90*** & $\mathbf{1 6 8}$ & $\mathbf{6 5 . 2}$ & $\mathbf{2 9 . 8 2}$ & $\mathbf{3 . 4 5}$ & $\mathbf{0 . 0 0 1}$ \\
q95*** & $\mathbf{2 5 7}$ & $\mathbf{8 3}$ & $\mathbf{3 8 . 6 5}$ & $\mathbf{4 . 5}$ & $\mathbf{0}$ \\
q99*** & $\mathbf{8 0 6}$ & $\mathbf{1 4 0 . 5}$ & $\mathbf{1 5 5 . 3 2}$ & $\mathbf{4 . 2 8}$ & $\mathbf{0}$ \\
$* * * * *$ & and $*$ denote significance in the difference be- \\
tween legal and illegal overcharge at the 99,95, and 90 \\
percent level. & \multicolumn{3}{|c}{} &
\end{tabular}


Table 5: Legal and illegal overcharges at different quantiles - Journal publication sample, $\mathrm{N}=704$

\begin{tabular}{lrrrrr}
\hline & Legal & Illegal & Std. Err. & $\mathrm{t}$ & $\mathrm{P}>\mathrm{t}$ \\
\hline \hline $\mathrm{q} 05$ & 0 & 0 & 0.56 & 0 & 1 \\
q10*** & $\mathbf{0}$ & $\mathbf{5}$ & $\mathbf{1 . 0 4}$ & $\mathbf{- 4 . 8 3}$ & $\mathbf{0}$ \\
q15*** & $\mathbf{1}$ & $\mathbf{7}$ & $\mathbf{1 . 2 0}$ & $\mathbf{- 4 . 9 8}$ & $\mathbf{0}$ \\
q20*** & $\mathbf{3 . 5}$ & $\mathbf{9 . 2}$ & $\mathbf{1 . 7 1}$ & $\mathbf{- 3 . 3 4}$ & $\mathbf{0 . 0 0 1}$ \\
q25** & $\mathbf{7 . 1}$ & $\mathbf{1 0 . 9}$ & $\mathbf{1 . 8 3}$ & $\mathbf{- 2 . 0 8}$ & $\mathbf{0 . 0 3 8}$ \\
q30 & 10 & 13.1 & 2.25 & -1.38 & 0.168 \\
q35 & 13.8 & 15.5 & 2.26 & -0.75 & 0.452 \\
q40 & 16.8 & 17.5 & 2.35 & -0.3 & 0.766 \\
q45 & 20 & 20.3 & 2.90 & -0.1 & 0.918 \\
q50 & 25 & 23 & 3.05 & 0.66 & 0.512 \\
q55* & $\mathbf{2 9}$ & $\mathbf{2 5}$ & $\mathbf{2 . 2 5}$ & $\mathbf{1 . 7 8}$ & $\mathbf{0 . 0 7 6}$ \\
q60 & 31 & 28 & 3.31 & 0.91 & 0.366 \\
q65 & 37.3 & 31.3 & 3.81 & 1.58 & 0.116 \\
q70*** & $\mathbf{4 5}$ & $\mathbf{3 3 . 7}$ & $\mathbf{3 . 7 7}$ & $\mathbf{3}$ & $\mathbf{0 . 0 0 3}$ \\
q75*** & $\mathbf{5 0}$ & $\mathbf{3 7}$ & $\mathbf{4 . 3 3}$ & $\mathbf{3}$ & $\mathbf{0 . 0 0 3}$ \\
q80*** & $\mathbf{6 0}$ & $\mathbf{4 2}$ & $\mathbf{6 . 6 4}$ & $\mathbf{2 . 7 1}$ & $\mathbf{0 . 0 0 7}$ \\
q85** & $\mathbf{7 3}$ & $\mathbf{5 0}$ & $\mathbf{7 . 7 4}$ & $\mathbf{2 . 9 7}$ & $\mathbf{0 . 0 0 3}$ \\
q90** & $\mathbf{1 0 0}$ & $\mathbf{6 0}$ & $\mathbf{1 8 . 5 1}$ & $\mathbf{2 . 1 6}$ & $\mathbf{0 . 0 3 1}$ \\
q95*** & $\mathbf{2 0 0 . 5}$ & $\mathbf{7 7 . 5}$ & $\mathbf{3 2 . 1 7}$ & $\mathbf{3 . 8 2}$ & $\mathbf{0}$ \\
q99* & $\mathbf{4 3 0}$ & $\mathbf{1 4 5 . 5}$ & $\mathbf{1 5 8 . 4 7}$ & $\mathbf{1 . 8}$ & $\mathbf{0 . 0 7 3}$
\end{tabular}

$* * *, * *$, and $*$ denote significance in the difference between legal and illegal overcharge at the 99,95 , and 90 percent level. 